\title{
BMJ Open Cervical cancer screening and HPV vaccine acceptability among rural and urban women in Kilimanjaro Region, Tanzania
}

\author{
Melissa S Cunningham, ${ }^{1}$ Emily Skrastins, ${ }^{1}$ Ryan Fitzpatrick, ${ }^{2}$ Priya Jindal, ${ }^{2}$ \\ Olola Oneko, ${ }^{3}$ Karen Yeates, ${ }^{1,2}$ Christopher M Booth, ${ }^{4}$ Jennifer Carpenter, ${ }^{1,2}$ \\ Kristan J Aronson ${ }^{1,4}$
}

To cite: Cunningham MS, Skrastins E, Fitzpatrick R, et al. Cervical cancer screening and HPV vaccine acceptability among rural and urban women in Kilimanjaro Region, Tanzania. BMJ Open 2015;5:e005828.

doi:10.1136/bmjopen-2014005828

- Prepublication history for this paper is available online. To view these files please visit the journal online (http://dx.doi.org/10.1136/ bmjopen-2014-005828).

MSC and ES are cofirst authors.

Received 2 June 2014 Revised 11 February 2015 Accepted 13 February 2015

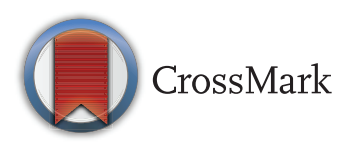

${ }^{1}$ Department of Public Health Sciences, Queen's University, Kingston, Ontario, Canada

2Faculty of Medicine, Queen's University, Kingston, Ontario, Canada

${ }^{3}$ Kilimanjaro Christian Medical Center, Moshi, Tanzania, Africa

${ }^{4}$ Division of Cancer Care and Epidemiology, Cancer

Research Institute, Queen's

University, Kingston, Canada

Correspondence to Dr Kristan J Aronson; aronson@queensu.ca

\section{ABSTRACT}

Objective: To determine cervical cancer screening coverage and the knowledge, attitudes and barriers toward screening tests among women in rural and urban areas of Tanzania, as well as explore how they view the acceptability of the HPV vaccine and potential barriers to vaccination.

Setting: A cross-sectional study using interviewadministered questionnaires was conducted using multistage random sampling within urban and rural areas in Kilimanjaro Region, Tanzania.

Participants: Women aged 18-55 were asked to participate in the survey. The overall response rate was $97.5 \%$, with a final sample of 303 rural and 272 urban dwelling women.

Primary and secondary outcome measures: Descriptive and simple test statistics were used to compare across rural and urban strata. Multivariate logistic regression models were used to estimate ORs and $95 \% \mathrm{Cls}$.

Results: Most women (82\%) reported they had heard of cervical cancer, while self-reported cervical cancer screening among women was very low $(6 \%)$. In urban areas, factors associated with screening were: older age (OR=4.14, $95 \% \mathrm{Cl} 1.86$ to 9.24 for ages $40-49$, and $\mathrm{OR}=8.38,95 \% \mathrm{Cl} 2.10$ to 33.4 for $>50$ years), having health insurance $(\mathrm{OR}=4.15,95 \% \mathrm{Cl} 1.52$ to 11.4), and having knowledge about cervical cancer $(\mathrm{OR}=5.81,95 \% \mathrm{Cl} 1.58$ to 21.4$)$. In contrast, among women residing in rural areas, only condom use (OR=6.44, 95\% Cl 1.12 to 37.1 ) was associated with screening. Women from both rural and urban areas had low vaccine-related knowledge; however, most indicated they would be highly accepting if it were readily available $(93 \%)$.

Conclusions: The current proportion of women screened for cervical cancer is very low in Kilimanjaro Region, and our study has identified several modifiable factors that could be addressed to increase screening rates. Although best implemented concurrently, the availability of prophylactic vaccination for girls may provide an effective means of prevention if they are unable to access screening in the future.

\section{Strengths and limitations of this study}

- This population-based sample was large and facilitated valid comparisons between rural and urban women in the Kilimanjaro region where cervical cancer is the leading cause of death.

- Multivariable modelling was used to identify factors associated with being screened.

- The survey results were self-reported and this may have compromised the validity of answers to sensitive questions.

\section{INTRODUCTION}

Cervical cancer is the third most common cancer among women worldwide, with approximately 500000 new cases occurring annually. ${ }^{1}$ Nearly $86 \%$ of these cases occur in low-income and middle-income countries. ${ }^{1}$ In addition to the burden imposed by its high morbidity and mortality, the disease largely affects women in their childbearing years and leads to significant losses for communities. ${ }^{2} 3$ Cervical cancer is the largest cause of potential years of life lost (PYLL) to cancer in the developing world, in some areas making a greater contribution to PYLL than competing diseases such as tuberculosis and AIDS. ${ }^{4}$ Cervical cancer is preventable primarily through prophylactic HPV vaccination and screening for precancerous lesions. ${ }^{5}$

The widespread use of the Papanicolau (Pap) screening test for over 50 years has progressively reduced the mortality of disease by $50-60 \%$ in high-resource countries. ${ }^{6}$ However, in developing countries, due to inadequate personnel and deficiencies in health system infrastructure, cervical cancer prevention remains largely opportunistic, often relying on low-resource visual inspection methods using acetic acid (VIA), or 
Lugol's iodine (VILI) with a 'see-and-treat' same-day approach. ${ }^{7}$ Reported uptake of even these screening services remains low, suggesting that there are barriers preventing women from being screened. ${ }^{89}$

Infection with human papillomavirus (HPV) is a necessary though not sufficient cause of cervical cancer. HPV strains 16 and 18 are responsible for approximately $70 \%$ of invasive cervical cancer cases worldwide while types 6 and 11 are responsible for $90 \%$ of anogenital warts cases. A quadrivalent vaccine protecting against these four strains is commercially available from Merck \& Co. (Gardasil) and a bivalent vaccine against the cervical cancer strains is available from GalxoSmithKline (Cervarix). Although organised cervical cancer screening and educational campaigns are recognised as important prevention methods for women today, combining these efforts with prophylactic vaccination of preadolescent girls is expected to substantially reduce the future burden of disease in low-resource countries. ${ }^{10}$ Unfortunately, the cost of the three-dose series (nearly US $\$ 400$ ) has made the vaccine largely unavailable to individuals who would be expected to benefit the most.

In Tanzania, cervical cancer is the most common female cancer with an estimated age-standardised incidence rate of 54 per 100000 women per year, a rate nearly five times higher than the incidence rate of the next most common cancer among both sexes combined. ${ }^{11}$ The comorbid epidemic of HIV/AIDS in the region and lack of screening has contributed to the high incidence of cervical cancer, and late detection and lack of treatment availability have resulted in a high cancerrelated mortality rate of 32 per 100000 women per year. ${ }^{11}$

Formative research surrounding current screening practices and attitudes towards vaccination is important for the success of prevention programmes and acceptance of the vaccine. ${ }^{12}$ In developed and developing countries, rural and urban regions tend to have different social and physical environments that contribute to differences in health outcomes. Inhabitants of rural regions are typically less able to access health services, an inequity that is particularly apparent in developing countries due to poorer overall healthcare infrastructure. ${ }^{13}$ The purpose of this research was to determine the knowledge, attitudes and barriers toward cervical cancer screening as well as explore the acceptability and perceived barriers toward HPV vaccination in a population-based sample of rural and urban women living in the Kilimanjaro Region that has not been formally sensitised with an education programme.

\section{METHODS}

Study design and data collection

A cross-sectional survey was conducted among women aged 18-55 years old in Moshi Rural and Moshi Urban, two districts in the Kilimanjaro Region of Tanzania. These districts were chosen in order to obtain representative samples of rural and urban living environments in the Kilimanjaro Region. A power calculation was used to estimate a required sample size of 300 women from both areas. The study questionnaire was designed in English, translated and intervieweradministered in Kiswahili, the official language of Tanzania. Questions included were modified from previous studies, newly designed using best survey practices by the research team, and guided by health behavioural theories to address the research objectives. ${ }^{14-16}$ Back translation and cognitive interviewing with a translator were conducted after the questionnaire was translated to establish content validity and clarity. The questionnaire was pilot-tested among 60 women in Moshi Rural and revised to reflect the population's sociodemographics. Surveying took place on weekdays in May-July 2012, using a stratified multistage sampling strategy. Within each district, five wards were randomly selected, followed by random selection of three villages and systematic sampling (with replacement) of houses. If more than one woman was eligible in a house, a random selection was made. Trained Tanzanian female research assistants paired with study investigators gave a brief introduction to the purpose of the study before both voluntary oral and written consent was obtained. Participants received no incentive to participate and the questionnaire took approximately $30 \mathrm{~min}$ to complete. Most questions were closed-response, consisting of Likert-type scales or Yes/No/Don't Know response choices. Brief education on the location and function of the cervix was provided during the survey for women who said they had never heard the word before.

The questionnaire was divided into nine sections, covering health and sociodemographic factors; cervical cancer awareness/knowledge, attitudes and barriers; and vaccination awareness, attitudes and barriers. In order to clarify survey motives and reiterate confidentiality some sections had brief narratives that were read to participants. For example, before the vaccination sections the following was read: "Human Papillomavirus (HPV) can cause cervical cancer. HPV is not the same as HIV. Vaccines are medications given to prevent the development of disease or illness."

Participants were considered to have an adequate knowledge of cervical cancer if they answered 'yes' to "Have you heard of (1) cancer and, (2) the cervix?" and "Have you heard of cervical cancer?" and 'women' to "Who can develop cervical cancer?" Awareness of cervical cancer was 'yes' to the question, "Have you heard of cervical cancer?" Acceptability of the HPV vaccine was evaluated by asking, "If the HPV vaccine became available in Tanzania, would you give permission for your daughter to receive it (or receive it yourself)?" (possible responses: definitely yes, probably yes, do not know, probably no and definitely no). For the purpose of this study, the outcome was conceptualised into a binomial response. Acceptors are those definitely accepting the vaccine (definitely yes $(=1)$ ) and those considered 
non-acceptors are those who gave less-accepting/hesitant responses (all other responses: probably yes, probably no, definitely no, don't know $(=0))$. The preamble to this question asked women to consider their daughters or hypothetical daughters/girls in the community, or if they were in the age range 10-25 they could answer considering themselves.

\section{Statistical analysis}

Rural and urban sample data were stratified a priori, and a purposeful selection strategy was used to select exploratory multivariable models identifying covariates that were independently associated with screening status. ${ }^{17}$ Comparisons for rural and urban strata were conducted using Pearson's $\chi^{2}$, Cochran-Armitage test for trend (modified $\chi^{2}$ for ordinal data) and Fisher's exact test $(\mathrm{n}<5)$. Wilcoxon rank-sum test was used to compare between rural and urban continuous, non-normally distributed variables. Generalised estimating equations with a logit link and exchangeable working correlation matrix were used to estimate ORs and 95\% CIs while accounting for the clustering within villages. Bivariate associations were calculated and variables associated at $\mathrm{p}<0.25$ were included in preliminary models and were subsequently removed until all remaining variables were significant, $p<0.05$. No variables had more than $5 \%$ missing data. Collinearity diagnostics and overall goodness-of-fit measures were assessed for each model. All statistical analyses were performed using SAS V.9.3 (SAS Institute Inc, Cary, North Carolina, USA).

\section{RESULTS}

The survey achieved a $97 \%$ and $98 \%$ response rate for rural and urban areas, respectively. Interviewer-reported validity and quality measures were collected for each survey, and those identified as invalid surveys by interviewers were excluded $(n=11)$. Eight participants were excluded for being outside the targeted 18-55 age group and women were categorised based on their reported living environments rather than sampling location, leading to a final study sample size of 272 urban and 303 rural women.

\section{Sociodemographic and health characteristics \\ of the sample}

Characteristics of the participants are shown in table 1 . Mean age was 34 years (SD: 9.7, range 18-55), and most were married $(66 \%)$ and in monogamous relationships $(96 \%)$. Urban women were younger, with greater education and higher socioeconomic status than women in rural areas. Most rural women $(77 \%)$ worked as farmers, while most urban women $(65 \%)$ worked or owned small businesses related to tourism, dining/restaurants and tailoring. Approximately $14 \%$ of women said that they had health insurance, with no differences between strata.

Health characteristics of participants are shown in table 2. Most women rated their health status as 'Fair' or
'Good', very few were smokers, and $1 \%$ reported themselves HIV positive. More women in the rural stratum reported ever having intercourse, although the mean age of sexual debut at about age 20 years was not different for rural and urban women. The majority $(69 \%$ rural and $59 \%$ urban) reported to only have had one sexual partner in their lifetime.

\section{Knowledge, attitudes and beliefs toward screening and vaccination among rural and urban women}

As presented in table 3, few women had ever been previously screened for cervical cancer (4\% rural, 9\% urban), while acceptability of screening among neverscreened women was very high $(90 \%)$. Of these women, a large proportion would be willing to travel over $2 \mathrm{~h}$ to access a screening clinic, and this proportion was significantly higher in the rural group than in the urban group $(60 \%$ vs $49 \%, \mathrm{p}<0.001)$. Many thought that cervical cancer was fatal, with significant differences between strata (91\% rural, $83 \%$ urban, $\mathrm{p}=0.004)$, and fewer thought that cervical cancer could be treated (63\% rural, 67\% urban, $\mathrm{p}=0.32$ ). There was a significant difference $(\mathrm{p}=0.02)$ in perception of their own personal risk for cervical cancer among strata (62\% rural, $71 \%$ urban).

The primary source of cervical cancer awareness was through the media, with $73 \%, 22 \%$ and $13 \%$ indicating the radio, television and newspaper, respectively. A higher proportion of rural women had heard of cervical cancer through the radio, while television was a more frequent source for urban women. Word-of-mouth was also a common route of information $(21 \%)$ and awareness through church members was more often reported by rural women. Relatively few women had heard of cervical cancer from a healthcare provider (13\%), and far fewer had heard of it through their education or schooling (1\%). Almost $30 \%$ of women had ever directly known someone with cervical cancer, which was similar among rural and urban women.

Few women had heard of the HPV vaccine, with significant differences in the proportion between rural and urban strata (table 4). Of those that had heard of the vaccine, the majority had awareness through the radio $(70 \%)$, television $(20 \%)$ or healthcare interactions $(12 \%)$. Despite low awareness, most believed $(80 \%)$ that their friends or family would support HPV vaccination. A similar proportion believed that they would have access to clinics or doctors to receive the vaccination, although this was significantly different $(\mathrm{p}=0.03)$ between rural and urban women $(75 \%$ and $83 \%$, respectively). In terms of general vaccination attitudes, nearly all women $(98 \%)$ believed that vaccinations were beneficial, and a moderate proportion $(65 \%)$ were willing to pay for vaccines if they were not offered free. Women were willing to travel to receive vaccinations, with many women agreeing to travel for longer than $2 \mathrm{~h}$ (55\% rural, $42 \%$ urban). 
Table 1 Sociodemographic characteristics among rural and urban women in the study population

\begin{tabular}{|c|c|c|c|c|}
\hline Characteristic & Total $(n=575) \%(n)$ & Rural $(n=303) \%(n)$ & Urban $(n=272) \%(n)$ & p Value \\
\hline \multicolumn{5}{|l|}{ Age } \\
\hline Mean $( \pm S D)$ & $33.8(9.7)$ & $36.2(9.7)$ & $31.2(8.9)$ & $<0.001^{*}$ \\
\hline$<30$ & $38.0(215)$ & $27.5(82)$ & 49.6 (133) & $<0.001 \dagger$ \\
\hline 30-39 & $32.9(186)$ & $34.2(102)$ & $31.3(84)$ & \\
\hline $40-49$ & $21.4(121)$ & $26.9(80)$ & $15.3(41)$ & \\
\hline$\geq 50$ & $7.8(44)$ & $11.4(34)$ & $3.7(10)$ & \\
\hline \multicolumn{5}{|l|}{ Marital status } \\
\hline Single & $13.7(78)$ & $10.3(31)$ & $17.6(47)$ & $<0.001 \dagger$ \\
\hline Partner & $8.6(49)$ & $4.3(13)$ & $13.5(36)$ & \\
\hline Married & $65.6(373)$ & 74.2 (224) & $55.8(149)$ & \\
\hline Separated & $6.7(38)$ & $4.6(14)$ & $9.0(24)$ & \\
\hline Divorced & $0.4(2)$ & $0.7(2)$ & $0.0(0)$ & \\
\hline Widow & $5.1(29)$ & $6.0(18)$ & $4.1(11)$ & \\
\hline \multicolumn{5}{|l|}{ Partnership type } \\
\hline Monogamy & $95.8(406)$ & $97.7(31)$ & $92.8(47)$ & $0.015 \dagger$ \\
\hline Polygamy & $4.3(18)$ & $2.3(6)$ & $7.2(12)$ & \\
\hline \multicolumn{5}{|l|}{ Religion } \\
\hline Christian & $82.9(474)$ & $95.0(287)$ & $69.3(187)$ & $<0.001 \dagger$ \\
\hline Muslim & $17.1(98)$ & $5.0(15)$ & 30.7 (83) & \\
\hline \multicolumn{5}{|l|}{ Culture } \\
\hline Chagga & $68.2(391)$ & $84.8(256)$ & $49.8(135)$ & $<0.001 \dagger$ \\
\hline Pare & $12.4(71)$ & $5.6(17)$ & $19.9(54)$ & \\
\hline Other & $19.4(111)$ & $9.6(29)$ & $30.3(82)$ & \\
\hline \multicolumn{5}{|c|}{ Monthly household income (TSH) } \\
\hline$<20000$ & 42.7 (241) & $62.2(184)$ & $21.2(57)$ & $<0.001 \ddagger$ \\
\hline $20000-39999$ & 22.5 (127) & $22.6(67)$ & $22.3(60)$ & \\
\hline $40000-59999$ & $11.2(63)$ & $7.4(22)$ & $15.2(41)$ & \\
\hline $60000-79999$ & $4.4(25)$ & $0.7(2)$ & $8.6(23)$ & \\
\hline $80000-99999$ & $3.2(18)$ & $1.7(5)$ & $4.8(13)$ & \\
\hline$\geq 100000$ & $16.1(91)$ & $5.4(16)$ & $27.9(75)$ & \\
\hline \multicolumn{5}{|l|}{ Occupation } \\
\hline Housewife/farmer & $51.0(284)$ & $76.6(226)$ & $22.1(58)$ & $<0.001 \S$ \\
\hline Small business & $38.4(214)$ & $15.0(44)$ & $64.6(170)$ & \\
\hline Professional & $2.0(11)$ & $1.4(4)$ & $2.7(7)$ & \\
\hline Student & $4.3(24)$ & $4.1(12)$ & $4.6(12)$ & \\
\hline Teacher & $2.3(13)$ & $1.7(5)$ & $3.0(8)$ & \\
\hline Health professional & $2.0(11)$ & $1.0(3)$ & $3.0(8)$ & \\
\hline \multicolumn{5}{|l|}{ Educational attainment } \\
\hline Primary or less & $8.4(48)$ & $10.9(33)$ & $5.5(15)$ & $<0.001 \ddagger$ \\
\hline Secondary (to Form 4) & $65.8(377)$ & 74.5 (225) & $56.1(152)$ & \\
\hline Secondary complete & $21.6(124)$ & $11.9(36)$ & $32.5(88)$ & \\
\hline College/University & $4.2(24)$ & $2.7(8)$ & $5.9(16)$ & \\
\hline \multicolumn{5}{|l|}{ Health insurance } \\
\hline No & $86.0(485)$ & $85.8(254)$ & $86.2(231)$ & $0.896 \dagger$ \\
\hline Yes & $14.0(79)$ & $14.2(42)$ & $13.8(37)$ & \\
\hline \multicolumn{5}{|l|}{ Number of births } \\
\hline Mean $( \pm S D)$ & $2.7(2.1)$ & $3.5(2.2)$ & $1.9(1.5)$ & $<0.001^{*}$ \\
\hline None & $14.7(84)$ & $7.6(23)$ & $22.6(61)$ & $<0.001 \ddagger$ \\
\hline $1-2$ & $36.8(211)$ & 30.7 (93) & $43.7(118)$ & \\
\hline $3-4$ & $31.1(178)$ & $34.3(104)$ & $27.4(74)$ & \\
\hline$>4$ & $17.5(100)$ & $27.4(83)$ & $6.3(17)$ & \\
\hline \multicolumn{5}{|l|}{ Daughter aged 10-25 } \\
\hline No & $60.4(347)$ & $51.5(156)$ & $70.2(191)$ & $<0.001 \dagger$ \\
\hline Yes & 39.7 (228) & $48.5(147)$ & $29.8(81)$ & \\
\hline
\end{tabular}

*Wilcoxon rank-sum test.

†Pearson's $\chi^{2}$ test.

¥Cochran-Armitage test for trend.

$\S$ Fisher's exact test. 
Table 2 Health characteristics among rural and urban women in the study population

\begin{tabular}{|c|c|c|c|c|}
\hline Characteristic & Total $(n=575) \%(n)$ & Rural $(n=303) \%(n)$ & Urban $(n=272) \%(n)$ & p Value \\
\hline \multicolumn{5}{|c|}{ Self-reported health status } \\
\hline Excellent & $3.2(18)$ & $2.7(8)$ & $3.7(10)$ & \multirow[t]{5}{*}{$0.001^{*}$} \\
\hline Very good & $6.4(36)$ & $6.7(20)$ & $5.9(16)$ & \\
\hline Good & 34.7 (197) & $26.3(78)$ & $44.1(119)$ & \\
\hline Fair & $51.3(291)$ & $58.6(174)$ & $43.3(117)$ & \\
\hline Poor & $4.4(25)$ & $5.7(17)$ & $3.0(8)$ & \\
\hline \multicolumn{5}{|l|}{ Smoker } \\
\hline No & $99.1(564)$ & $99.3(298)$ & $98.9(266)$ & \multirow[t]{2}{*}{$0.671 \dagger$} \\
\hline Yes & $0.9(5)$ & $0.7(2)$ & $1.1(3)$ & \\
\hline \multicolumn{5}{|l|}{ HIV positive } \\
\hline No & $99.0(567)$ & $99.3(300)$ & $98.5(267)$ & \multirow[t]{2}{*}{$0.429 \dagger$} \\
\hline Yes & $0.9(5)$ & $0.7(2)$ & $1.1(3)$ & \\
\hline \multicolumn{5}{|c|}{ Currently using contraception (any) } \\
\hline No & 57.5 (319) & $55.6(164)$ & $59.6(155)$ & \multirow[t]{2}{*}{ 0.339ł } \\
\hline Yes & $42.5(236)$ & $44.4(131)$ & $40.4(105)$ & \\
\hline \multicolumn{5}{|c|}{ Ever had intercourse } \\
\hline No & $7.0(40)$ & $3.3(10)$ & $11.1(30)$ & \multirow[t]{2}{*}{$<0.001 \ddagger$} \\
\hline Yes & $93.0(533)$ & 96.7 (292) & $88.9(241)$ & \\
\hline \multicolumn{5}{|c|}{ Age of sexual debut } \\
\hline Mean $( \pm S D)$ & $19.8(3.2)$ & $19.6(3.2)$ & $19.9(3.3)$ & $0.794 \S$ \\
\hline$<16$ & $6.4(32)$ & $6.5(18)$ & $6.5(14)$ & \multirow[t]{3}{*}{$0.973 \ddagger$} \\
\hline $16-23$ & $82.1(409)$ & $82.4(229)$ & $81.8(180)$ & \\
\hline$\geq 24$ & $11.5(57)$ & $11.2(31)$ & $11.8(26)$ & \\
\hline \multicolumn{5}{|c|}{ Lifetime number of sexual partners } \\
\hline None & $7.2(41)$ & $3.3(10)$ & $11.7(31)$ & \multirow[t]{4}{*}{$0.201^{*}$} \\
\hline 1 & $64.1(363)$ & $68.8(207)$ & $58.9(156)$ & \\
\hline $2-3$ & $25.6(145)$ & $24.9(75)$ & $26.4(70)$ & \\
\hline$\geq 4$ & $3.0(17)$ & $3.0(9)$ & $3.0(8)$ & \\
\hline
\end{tabular}

\section{Perceived barriers to cervical cancer screening and HPV} vaccination among rural and urban women

Women were asked to select all reasons why they had not yet been screened for cervical cancer (table 5). The largest barrier reported by women was being unaware that preventative screening tests exist $(67 \%)$. In addition, about half anticipated not being able to afford the test or the travel costs associated with it, and a quarter considered the opportunity cost of taking time off work to be a barrier. Travel distance to healthcare facilities was also a prohibitive factor and was more frequently reported among rural than urban women $(27 \%$ vs $12 \%, \mathrm{p}<0.001)$. The greatest concern (50\% rural, $46 \%$ urban, $\mathrm{p}=0.40$ ) among women regarding the HPV vaccine was the perceived costs associated with the vaccination. This was followed by shared concerns among women in strata regarding the unknown future side effects $(41 \%)$, short-term side effects $(20 \%)$, safety of the vaccine's administration (19\%), social acceptability $(16 \%)$, availability $(13 \%)$, effectiveness $(11 \%)$ and conformity with religious beliefs $(6 \%)$. The concern of promiscuity/encouragement of early sex was significantly different between strata $(p<0.001)$, with more women in rural areas concerned. Significantly more women in rural areas were also concerned about previous testing of the vaccine's safety as compared to urban women (11\% rural, $6 \%$ urban, $\mathrm{p}=0.03$ ).

\section{Determinants of cervical cancer screening status}

In a multivariate model of women in the rural stratum, condom users had higher odds of being screened for cervical cancer (OR=6.44, 95\% CI 1.12 to 37.1). Among urban women, older age groups had significantly higher odds of being screened (OR=4.14, 95\% CI 1.86 to 9.24 and $\mathrm{OR}=8.38,95 \%$ CI 2.10 to 33.4 for the $40-49$ and $>50$ age groups, respectively) and we found a marginal association that single women had lower odds of being screened than married women $(\mathrm{OR}=0.11,95 \%$ CI 0.01 to 1.04$)$. Health insurance $(\mathrm{OR}=4.15,95 \%$ CI 1.52 to 11.4) and knowledge of cervical cancer $(\mathrm{OR}=5.81,95 \%$ CI 1.58 to 21.4) were strongly associated with being screened among urban women.

\section{Acceptability of HPV vaccination}

In rural and urban strata, acceptance of the HPV vaccine among participants was very high, with $93 \%$ of participants intending to definitely accept the vaccine if it were to become available in Tanzania. Women were also asked to predict their husband or partner's 
Table 3 Cervical cancer knowledge and attitudes among rural and urban women in the study population

\begin{tabular}{|c|c|c|c|c|}
\hline Variable & $\begin{array}{l}\text { Total } \\
(n=575) \\
\%(n)\end{array}$ & $\begin{array}{l}\text { Rural } \\
(n=303) \\
\%(n)\end{array}$ & $\begin{array}{l}\text { Urban } \\
(n=272) \\
\%(n)\end{array}$ & p Valu \\
\hline \multicolumn{5}{|c|}{ Aware of the disease $†$} \\
\hline No & $17.6(101)$ & 17.5 & $17.7(48)$ & \multirow[t]{2}{*}{0.96} \\
\hline Yes & & (250) & $82.4(224)$ & \\
\hline \multicolumn{5}{|c|}{ Source of awareness } \\
\hline Church & $8.44(40)$ & $13.6(34)$ & $2.68(6)$ & $<0.001$ \\
\hline $\begin{array}{l}\text { Family/ } \\
\text { friend }\end{array}$ & $20.5(97)$ & $20.4(51)$ & $20.5(46)$ & 0.97 \\
\hline Healthcare & (60) & & (26) & 0.51 \\
\hline Stud & 1.27( & & $1.79(224)$ & $0.43 \ddagger$ \\
\hline New & & & & 0.20 \\
\hline Rad & 345) & 01) & 44) & $<0.001$ \\
\hline Television & & & & $<0.001$ \\
\hline \multicolumn{5}{|c|}{ Adequate knowledge cervical cancer† } \\
\hline No & $86.9(411)$ & $91.2(277)$ & (184) & \multirow[t]{2}{*}{$<0.001$} \\
\hline Yes & $13.1(62)$ & $8.82(22)$ & & \\
\hline \multicolumn{5}{|c|}{ Known someone with cervical cancer } \\
\hline No & $73.8(417)$ & $71.7(213)$ & $76.1(204)$ & \multirow[t]{2}{*}{0.235} \\
\hline Yes & $26.2(148)$ & $28.3(84)$ & & \\
\hline \multicolumn{5}{|c|}{ Ever screened for cervical cancer } \\
\hline No & & $95.7(290)$ & $5(248)$ & \multirow[t]{2}{*}{0.040} \\
\hline Yes & $6.8(39)$ & & $8.5(23)$ & \\
\hline \multicolumn{5}{|c|}{ If not, would accept cervical cancer screening } \\
\hline No & $10.2(55)$ & $10.9(32)$ & $9.4(23)$ & \multirow[t]{2}{*}{0.557} \\
\hline Yes & & 89 & 223) & \\
\hline \multicolumn{5}{|c|}{ Max distance willing to travel } \\
\hline & & & & \multirow[t]{3}{*}{$<0.01$} \\
\hline $1 \mathrm{~h}$ & & & & \\
\hline$\geq 2 \mathrm{~h}$ & $55.0(214)$ & $60.0(126)$ & & \\
\hline \multicolumn{5}{|c|}{ Believes cervical cancer is fatal } \\
\hline No & $12.8(73)$ & $9.0(27)$ & & \multirow[t]{2}{*}{0.004} \\
\hline Yes & $87.2(498)$ & $91.0(273)$ & 225) & \\
\hline \multicolumn{5}{|c|}{ Believes cervical cancer can be treated } \\
\hline No & & & & \multirow[t]{2}{*}{0.317} \\
\hline Yes & $65.1(367)$ & $63.1(185)$ & $67.2(182)$ & \\
\hline \multicolumn{5}{|c|}{ Believes they are at risk for cervical cancer } \\
\hline No & $33.4(192)$ & $37.6(114)$ & $28.7(78)$ & \multirow[t]{2}{*}{0.023} \\
\hline Yes & $66.6(383)$ & $62.4(189)$ & $71.3(194)$ & \\
\hline \multicolumn{5}{|c|}{ Believes their daughter is at risk for cervical cancer } \\
\hline No & $35.1(80)$ & $38.8(57)$ & $28.4(23)$ & \multirow[t]{2}{*}{0.116} \\
\hline Yes & $64.9(148)$ & $61.2(90)$ & $71.6(58)$ & \\
\hline
\end{tabular}

*Pearson's $\chi^{2}$.

†Adequate knowledge of cervical cancer was 'yes' to "Have you heard of (1) cancer and, (2) the cervix?" and "Have you heard of cervical cancer?" and 'women' to "Who can develop cervical cancer?" Awareness of cervical cancer was 'yes' to "Have you heard of cervical cancer?"

‡Fisher's exact test.

acceptance of the vaccine: while there was no difference across urban/rural strata, women's predictions of their husband or partner's intention to definitely accept the vaccine was lower $(64 \%)$.

\section{DISCUSSION}

In this population-based sample of rural and urban women from the Kilimanjaro Region, Tanzania, the
Table 4 Human papillomavirus (HPV) knowledge and attitudes among rural and urban women in the study population

\begin{tabular}{|c|c|c|c|c|}
\hline Variable & $\begin{array}{l}\text { Total } \\
(n=575) \\
\%(n)\end{array}$ & $\begin{array}{l}\text { Rural } \\
(n=303) \\
\%(n)\end{array}$ & $\begin{array}{l}\text { Urban } \\
(n=272) \\
\%(n)\end{array}$ & p Value* \\
\hline \multicolumn{5}{|c|}{ Heard of the HPV vaccine } \\
\hline No & $91.0(523)$ & $88.5(268)$ & $93.8(255)$ & \multirow[t]{2}{*}{0.027} \\
\hline Yes & $9.0(52)$ & $11.6(35)$ & $6.3(17)$ & \\
\hline \multicolumn{5}{|c|}{ Willing to definitely accept the HPV vaccine } \\
\hline No & $6.8(39)$ & $7.0(21)$ & $6.6(18)$ & \multirow[t]{2}{*}{0.904} \\
\hline Yes & $93.1(532)$ & $93.0(280)$ & $93.3(252)$ & \\
\hline \multicolumn{5}{|c|}{$\begin{array}{l}\text { Believes husband/partner will definitely accept HPV } \\
\text { vaccine }\end{array}$} \\
\hline No & $36.3(205)$ & $37.9(113)$ & $34.3(92)$ & \multirow[t]{2}{*}{0.375} \\
\hline Yes & $63.8(361)$ & $62.1(185)$ & $65.7(176)$ & \\
\hline \multicolumn{5}{|c|}{ Believes family/friends will support the HPV vaccine } \\
\hline No & $19.9(114)$ & $21.6(65)$ & $18.1(49)$ & \multirow[t]{2}{*}{0.294} \\
\hline Yes & $80.1(458)$ & $78.4(236)$ & $81.9(222)$ & \\
\hline \multicolumn{5}{|c|}{$\begin{array}{l}\text { Believes they are able to access a clinic/doctor for } \\
\text { vaccination }\end{array}$} \\
\hline No & $21.0(120)$ & $24.6(74)$ & $17.0(46)$ & \multirow[t]{2}{*}{0.027} \\
\hline Yes & $79.0(451)$ & $75.4(227)$ & $83.0(224)$ & \\
\hline \multicolumn{5}{|c|}{ Believes vaccines are beneficial } \\
\hline No & $1.6(9)$ & $1.0(3)$ & $2.2(6)$ & \multirow[t]{2}{*}{ 0.319† } \\
\hline Yes & $98.4(564)$ & 99.0 (299) & $97.8(265)$ & \\
\hline \multicolumn{5}{|c|}{ Willing to pay for vaccines } \\
\hline No & $35.2(201)$ & $33.9(102)$ & $36.7(99)$ & \multirow[t]{2}{*}{0.488} \\
\hline Yes & $64.8(370)$ & $66.0(199)$ & $63.3(171)$ & \\
\hline \multicolumn{5}{|c|}{ Max. time willing to travel for vaccination } \\
\hline$<30 \min$ & $25.7(146)$ & $20.8(62)$ & $31.1(84)$ & \multirow[t]{3}{*}{$<0.001^{\ddagger}$} \\
\hline $1 \mathrm{~h}$ & $25.7(146)$ & $24.2(72)$ & $27.4(74)$ & \\
\hline$\geq 2 \mathrm{~h}$ & $48.6(276)$ & $55.0(164)$ & $41.5(112)$ & \\
\hline \multicolumn{5}{|c|}{$\begin{array}{l}{ }^{*} \text { Pearson's } \chi^{2} \text {. } \\
\text { †Fisher's exact test. } \\
\text { †Cochran-Armitage test for trend. }\end{array}$} \\
\hline
\end{tabular}

prevalence of screening for cervical cancer was extremely low at $6 \%$, in close agreement with the 5-year screening prevalence estimated for developing countries by the WHO $(5 \%) .{ }^{6}$ Screening in rural and urban women in this study was lower than the $23 \%$ figure reported among rural women in one previous study of the Kilimanjaro region ${ }^{18}$; selective or clustered sampling may have biased estimates in other studies. In terms of personal risk for cervical cancer, the majority of women in this study perceived that they were susceptible to the disease. This finding is encouraging, as some studies in the developing world have reported that a large proportion of women do not believe they are at risk. ${ }^{19}$

Despite differences on several measures, and findings of low vaccine-related knowledge, both rural and urban groups reported high acceptance of the HPV vaccine if it were to be available. This is consistent with other lowresource countries in sub-Saharan Africa, and due to low knowledge may represent a general attitude towards vaccinations or an attitude toward a vaccine preventing cancer. Tanzania currently vaccinates against six diseases through the Expanded Programme on Immunisation 
Table 5 Self-reported barriers or concerns toward cervical cancer screening and HPV vaccination among rural and urban women in the study population

\begin{tabular}{|c|c|c|c|c|}
\hline Barrier or concern & Total $(n=478) \%(n)$ & Rural $(n=258) \%(n)$ & Urban $(n=220) \%(n)$ & p Value* \\
\hline \multicolumn{5}{|l|}{ Cervical cancer screening } \\
\hline Unaware of screening tests & 66.5 (322) & $63.4(166)$ & $70.3(156)$ & $0.108 \dagger$ \\
\hline Cannot take time off work & 25.6 (124) & $25.6(67)$ & $25.7(57)$ & $0.979 \dagger$ \\
\hline Other priorities in household & $3.72(18)$ & $6.11(16)$ & $0.90(2)$ & $0.003 \ddagger$ \\
\hline Husband would not approve & $4.13(20)$ & $5.75(15)$ & $2.25(5)$ & $0.067 \ddagger$ \\
\hline Does not have someone to go with & $7.02(34)$ & $8.78(23)$ & $4.95(11)$ & $0.101 \dagger$ \\
\hline Cannot afford to pay for a test & $49.3(239)$ & $48.3(127)$ & $50.5(112)$ & $0.635 \dagger$ \\
\hline Travel distance is too far & $20.0(97)$ & $26.6(70)$ & $12.2(27)$ & $<0.001 \dagger$ \\
\hline \multicolumn{5}{|l|}{ HPV vaccination§ } \\
\hline Safety of the vaccine's administration & $19.1(110)$ & $18.8(57)$ & $19.5(53)$ & $0.840 \dagger$ \\
\hline Short-term side effects & $19.7(113)$ & $18.2(55)$ & $21.3(58)$ & $0.339 \dagger$ \\
\hline Unknown future side effects & 40.7 (234) & $42.2(128)$ & $39.0(106)$ & $0.425 \dagger$ \\
\hline Risk of encouraging earlier sex & $14.3(82)$ & $19.8(60)$ & $8.1(22)$ & $<0.001 \dagger$ \\
\hline Conformity with religious beliefs & $6.3(36)$ & $7.9(24)$ & $4.4(12)$ & $0.080 \dagger$ \\
\hline Effectiveness of vaccine & $10.6(61)$ & $12.9(39)$ & $8.1(22)$ & $0.063 \dagger$ \\
\hline Cost of vaccination & $47.8(275)$ & 49.5 (150) & $46.0(125)$ & $0.395 \dagger$ \\
\hline Availability & $13.0(75)$ & $13.9(42)$ & $12.2(33)$ & $0.538 \dagger$ \\
\hline Previous testing of vaccine's safety & $8.2(47)$ & $10.6(32)$ & $5.5(15)$ & $0.027 \dagger$ \\
\hline Social acceptability & $15.5(89)$ & $16.2(49)$ & $14.7(40)$ & $0.628 \dagger$ \\
\hline
\end{tabular}

${ }^{*}$ Note: choosing multiple barriers/concerns were allowed.

†Pearson's $\chi^{2}$ test.fFisher's exact test.

$\S$ Note: sample size for HPV vaccination portion of the survey was the follows: total $(n=575)$, rural $(n=303)$, urban $(n=272)$.

HPV, human papillomavirus.

(EPI) and uptake of these vaccinations has been high, reaching $75 \%$ of children aged $12-23$ months. ${ }^{20}$

Our findings suggest that popular media sources, such as the TV and radio, are important sources for cervical cancer and HPV-related knowledge dissemination, consistent with findings from other low-resource areas. ${ }^{21}$ The content or accuracy of these messages was not investigated in the present study and may be a future research direction; empirical studies examining message framing of the HPV vaccine have been studied mostly within the USA, ${ }^{22-24}$ and there may be cultural preferences to be explored. Community-based routes of information, such as church, were also common in rural areas.

Within the past few years there has been a growing body of literature on the psychosocial aspects of HPV vaccination within sub-Saharan African countries, ${ }^{21}$ 25-38 revealing that HPV vaccine-related awareness and knowledge is quite low, however intention to vaccinate with the HPV vaccine is high. Most studies were conducted in urban or semiurban environments, and were convenience samples collected from clinics, communities and schools/universities. Recommendation from a healthcare provider and endorsement by the government were two important cues to action for vaccine acceptance, and perceived barriers such as cost and accessibility appeared to be important. ${ }^{39}$

Although women themselves reported their intention of high acceptance of a HPV vaccine, their husband/ partner's acceptance of the vaccine was lower. Women may not have felt confident to speak on their behalf of their partner; however, in general it has been suggested that women make the majority of health decisions for their children in these contexts. ${ }^{26}{ }^{28}$ Nevertheless, when asked about decision-making, women expected that the decision to vaccinate would be made by both parents together, and so investigating vaccination attitudes among men may be of interest to future studies.

In general, reported barriers to cervical cancer screening were similar among rural and urban women. Similar to findings from other studies in developing countries, ${ }^{40-42}$ the primary barrier to being screened was not knowing that preventative screening tests existed, along with socioeconomic factors. Our findings on perceived barriers towards vaccination suggest that financial barriers are an important concern among both groups, consistent with other studies. ${ }^{27}{ }^{30}$ Although the vaccine is expected to be administered for free, the financial burden associated with access to the vaccination should be minimised, and further reductions at the policy level may be important towards increasing access for those outside the age range who wish to vaccinate ${ }^{43}$ Concerns of the vaccine's safety and side effects are also important barriers to address; and, history has shown that misinformation generated by publicity campaigns, such as that during the tetanus toxoid vaccination in Tanzania, present major barriers toward acceptance. ${ }^{44}$

In terms of the determinants of screening status, among the urban strata, older women were more likely to have ever been screened for cervical cancer, which may reflect more lifetime contact with health services and opportunities to be screened. Marital status was 
marginally associated with screening; independently of age, single women were less likely to be screened than partnered or married women. This association is consistent with several other studies in developing settings, including an analysis of World Health Survey data in 14 low-income countries. ${ }^{45-47}$ Lack of social support may manifest as a screening barrier in women who do not want to visit screening clinics alone, particularly when they have to travel long distances to access them. ${ }^{41}{ }^{42}$ Studies of cervical screening have also observed that women are often encouraged to be screened by members of their social network, including family members, partners and friends. ${ }^{47-49}$ Cervical cancer knowledge was a strong predictor of screening status, though only among urban women. While directionality of the association cannot be assessed in this crosssectional study, knowledge of the disease and its prevention may motivate women to seek screening themselves and has been noted as an important determinant in most studies of cervical screening uptake. ${ }^{48-50}$ Health insurance was associated with being screened, which is consistently supported as an important predictor of screening status in developed and developing countries. $^{39} 4050$

In contrast, in rural areas, access barriers may prevent women from being screened even if they have previous knowledge of screening and/or health insurance. A previous study of screening uptake in the Moshi Rural district of Kilimanjaro noted that when all factors were examined simultaneously, only living close to a screening facility and knowledge of cervical cancer were significantly associated with screening status, and this knowledge may have been gained through the screening procedure itself. ${ }^{18}$ Condom use was associated with increased likelihood of screening in the rural sample. Women who rely on condoms as a contraceptive method may be more empowered, health conscious, have supportive partners and/or regular access to healthcare clinics.

These findings are timely given the recent announcements of upcoming vaccine demonstration projects in Tanzania. Strengths include the use of a multistage sampling strategy to investigate a population-based sample that was large enough to make valid rural and urban comparisons. Comparison of the demographic characteristics of participants to findings from the nationwide Demographic Health Survey (DHS) conducted in Tanzania in 2010 illustrates that our sample has concordant findings on education, parity, smoking status and sexual behaviours such as contraception use. ${ }^{20}$ Although the sample is believed to be representative of the Kilimanjaro Region, the findings may not be generalisable to other regions with different sociodemographic characteristics. Another strength of this study is the use of multivariable modelling to identify associations with screening status while taking into account the clustered nature of the data. Although the survey was pilot-tested, a limitation of this study is the use of a survey that has not been tested for validity or reliability. The survey results were self-reported and social desirability may have influenced answers to sensitive questions, such as those on sexual behaviours.

Cervical cancer screening programmes that are affordable, acceptable, and effective remain a priority, and the ethics of implementing such programmes should be considered in light of the availability of treatment. The introduction of a quadrivalent vaccine that protects against $70 \%$ of cervical cancer cases is a promising and important shift toward prevention of this disease and recently announced demonstration plans by Global Alliance for Vaccines and Immunization (GAVI) represent an important step toward national introduction of the HPV vaccine in Tanzania.

Our findings suggest that acceptance of screening and HPV vaccination are high; however, public education on both are required, and there are particular concerns that could be addressed within campaigns in order to ensure high, widespread acceptance, including emphasising the safety of the HPV vaccine and the importance of screening even in asymptomatic women. In the future, research may focus on conducting in-depth interviews or focus groups to study the attitudes of men towards the HPV vaccine or assessing general attitudes towards the vaccinations of boys; it may also be of interest to reassess attitudes and barriers once educational and social mobilisation campaigns have occurred in these areas, as well as studying vaccine message framing and effectiveness in Tanzania.

Twitter Follow Karen Yeates at @yeatesk

Acknowledgements The authors would like to acknowledge and thank the women who participated in this study. The authors also acknowledge the work of our research assistants and colleagues at Pamoja Tunaweza Women's Center (Moshi, Tanzania), and would like to especially thank Peter Kivumbi for his work on this project.

Contributors MSC, ES, RF and PJ performed data collection under the guidance of all other authors. MSC and ES performed the statistical analysis and drafted the manuscript with the support of KJA. All authors contributed to the conception, study design and review of this paper.

Funding This work was supported by the Pure Art Foundation and the authors of this study.

Competing interests None.

Patient consent Obtained.

Ethics approval Health Sciences Research Ethics Board (Queen's University, Canada), the Kilimanjaro Christian Medical Center Ethics Board and the National Institute for Medical Research (Tanzania).

Provenance and peer review Not commissioned; externally peer reviewed.

Data sharing statement Additional data collected during this survey are available on request to KJA.

Open Access This is an Open Access article distributed in accordance with the Creative Commons Attribution Non Commercial (CC BY-NC 4.0) license, which permits others to distribute, remix, adapt, build upon this work noncommercially, and license their derivative works on different terms, provided the original work is properly cited and the use is non-commercial. See: http:// creativecommons.org/licenses/by-nc/4.0/ 


\section{REFERENCES}

1. De Sanjosé $S$, Serrano $B$, Castellsagué $X$, et al. Human papillomavirus (HPV) and related cancers in the Global Alliance for Vaccines and Immunization (GAVI) countries. A WHO/ICO HPV Information Centre Report [Internet]. 2012. http://www.hpvcentre.net/ link media/GAVI Report 2012 doc.pdf

2. Schiffman M, Castle PE, Jeronimo J, et al. Human papillomavirus and cervical cancer. Lancet 2007;370:890-907.

3. Franco EL, Schlecht NF, Saslow D. The epidemiology of cervical cancer. Cancer J Sudbury Mass 2003;9:348-59.

4. Yang BH, Bray FI, Parkin DM, et al. Cervical cancer as a priority for prevention in different world regions: an evaluation using years of life lost. Int J Cancer 2004;109:418-24.

5. Nour NM. Cervical cancer: a preventable death. Rev Obstet Gynecol 2009;2:240-4.

6. World Health Organization (WHO). Control of cancer of the cervix uteri. Bull World Health Organ 1986;64:607-18.

7. WHO prevention of cervical cancer through screening using visual inspection with acetic acid (VIA) and treatment with cryotherapy [Internet]. WHO. (cited 26 August 2013). http://www.who.int/ reproductivehealth/publications/cancers/9789241503860/en/

8. Tomljenovic L, Shaw CA. Human papillomavirus (HPV) vaccine policy and evidence-based medicine: are they at odds? Ann Med 2013;45:182-93.

9. Gakidou E, Nordhagen S, Obermeyer Z. Coverage of cervical cancer screening in 57 countries: low average levels and large inequalities. PLoS Med 2008;5:e132.

10. World Health Organization (WHO). Human papillomavirus vaccines WHO position paper. 2009 Apr 117-32. Report No 15.

11. Globocan 2012: estimated cancer incidence, mortality and prevalence worldwide in 2012 [Internet]. Tanzania. (cited 30 May 2014). http://globocan.iarc.fr/Pages/fact_sheets_population.aspx

12. Larson HJ, Brocard P, Garnett G. The India HPV-vaccine suspension. Lancet 2010;376:572-3.

13. In her lifetime: female morbidity and mortality in Sub-Saharan Africa [Internet]. (cited 5 May 2014). http://www.nap.edu/catalog.php? record id $=5112$

14. Harkness JA, van de Vijver FJR, Mohler PhP. Cross-cultural survey methods. J. Wiley; 2003:440.

15. Fowler FJ. Survey research methods. SAGE Publications; 2009:201

16. Poss JE. Developing a new model for cross-cultural research: synthesizing the health belief model and the theory of reasoned action. Adv Nurs Sci 2001;23:1-15.

17. Bursac Z, Gauss CH, Williams DK, et al. Purposeful selection of variables in logistic regression. Source Code Biol Med 2008;3:17.

18. Lyimo FS, Beran TN. Demographic, knowledge, attitudinal, and accessibility factors associated with uptake of cervical cancer screening among women in a rural district of Tanzania: three public policy implications. BMC Public Health 2012;12:22.

19. Ibekwe CM, Hoque ME, Ntuli-Ngcobo B. Perceived susceptibility of cervical cancer screening among women attending Mahalapye district hospital, Botswana. South Afr J Epidemiol Infect 2010;25:16-21.

20. National Bureau of Statistics, ICF Macro. Tanzania Demographic and Health Survey 2010 [Internet]. Dar es Salaam, Tanzania; 2011 Apr 482. http://www.measuredhs.com/pubs/pdf/FR243/FR243\% 5B24June2011\%5D.pdf

21. Makwe CC, Anorlu RI, Odeyemi KA. Human papillomavirus (HPV) infection and vaccines: knowledge, attitude and perception among female students at the University of Lagos, Lagos, Nigeria. J Epidemiol Glob Heal 2012;2:199-206.

22. Bigman CA, Cappella JN, Hornik RC. Effective or ineffective: attribute framing and the human papillomavirus (HPV) vaccine. Patient Educ Couns 2010;81(Suppl):S70-6.

23. Gerend MA, Shepherd JE. Using message framing to promote acceptance of the human papillomavirus vaccine. Health Psychol 2007;26:745-52.

24. Sperber NR, Brewer NT, Smith JS. Influence of parent characteristics and disease outcome framing on HPV vaccine acceptability among rural, Southern women. Cancer Causes Control 2007;19:115-18.

25. Iliyasu Z, Abubakar IS, Aliyu MH, et al. Cervical cancer risk perception and predictors of human papilloma virus vaccine acceptance among female university students in northern Nigeria. J Obstet Gynaecol 2010;30:857-62.

26. Ports KA, Reddy DM, Rameshbabu A. Barriers and facilitators to HPV vaccination: perspectives from Malawian women. Women Health 2013;53:630-45.
27. Francis SA, Nelson J, Liverpool J, et al. Examining attitudes and knowledge about HPV and cervical cancer risk among female clinic attendees in Johannesburg, South Africa. Vaccine 2010;28:8026-32.

28. Francis SA, Battle-Fisher M, Liverpool J, et al. A qualitative analysis of South African women's knowledge, attitudes, and beliefs about HPV and cervical cancer prevention, vaccine awareness and acceptance, and maternal-child communication about sexual health. Vaccine 2011;29:8760-5.

29. Harries J, Moodley J, Barone MA, et al. Preparing for HPV vaccination in South Africa: key challenges and opinions. Vaccine 2009;27:38-44.

30. Coleman MA, Levison J, Sangi-Haghpeykar H. HPV vaccine acceptability in Ghana, West Africa. Vaccine 2011;29:3945-50.

31. DiAngi YT, Panozzo CA, Ramogola-Masire D, et al. A Crosssectional study of HPV vaccine acceptability in Gaborone, Botswana. PLOS ONE 2011;6:e25481.

32. Becker-Dreps S, Otieno WA, Brewer NT, et al. HPV vaccine acceptability among Kenyan women. Vaccine 2010;28:4864-7.

33. Katahoire RA, Jitta J, Kivumbi G, et al. An assessment of the readiness for introduction of the HPV vaccine in Uganda. Afr $J$ Reprod Health [Internet]. 2008 (cited 7 Aug 2013);12. http://www. ajol.info/index.php/ajrh/article/viewFile/55644/44117

34. W Liu F, Vwalika B. Cervical cancer and HPV vaccination: knowledge and attitudes of adult women in Lusaka, Zambia. $J$ Vaccines Vaccin [Internet] 2012 (cited 7 Aug 2013);3. http://www. omicsonline.org/2157-7560/2157-7560-3-138.digital/ 2157-7560-3-138.html

35. Omondi-Ogutu, M'Imunya JM. Parental acceptance of human papilloma virus vaccine for their pre-pubertal and teenage daughters. East Afr Med J 2013;88:163-70.

36. Poole DN, Tracy JK, Levitz L, et al. A cross-sectional study to assess HPV knowledge and HPV vaccine acceptability in Mali. PLOS ONE 2013;8:e56402.

37. Remes P, Selestine V, Changalucha J, et al. A qualitative study of HPV vaccine acceptability among health workers, teachers, parents, female pupils, and religious leaders in northwest Tanzania. Vaccine 2012;30:5363-7.

38. Rositch AF, Gatuguta A, Choi RY, et al. Knowledge and acceptability of Pap smears, self-sampling and HPV vaccination among adult women in Kenya. PLoS ONE 2012;7:e40766

39. Cunningham MS, Davison $\mathrm{C}$, Aronson K. HPV vaccine acceptability: a systematic review. Prev Med 2014;69:274-9.

40. McFarland DM. Cervical cancer and Pap smear screening in Botswana: knowledge and perceptions. Int Nurs Rev 2003;50:167-75.

41. Basu P, Sarkar S, Mukherjee S, et al. Women's perceptions and social barriers determine compliance to cervical screening: results from a population based study in India. Cancer Detect Prev 2006;30:369-74.

42. Ngugi $\mathrm{CW}$, Boga $\mathrm{H}$, Muigai $\mathrm{AWT}$, et al. Factors affecting uptake of cervical cancer early detection measures among women in Thika, Kenya. Health Care Women Int 2012;33:595-613.

43. GAVI. Millions of girls in developing countries to be protected against cervical cancer thanks to new HPV vaccine deals-2013-Press releases-News_Library_GAVI Alliance [Internet]. 2013 (cited 13 Aug 2013). http://www.gavialliance.org/library/news/press-releases/ 2013/hpv-price-announcement/

44. Milstien J, David Griffin P, Lee JW. Damage to immunisation programmes from misinformation on contraceptive vaccines. Reprod Health Matters 1995;3:24-8.

45. Watkins MM, Gabali C, Winkleby M, et al. Barriers to cervical cance screening in rural Mexico. Int J Gynecol Cancer Off J Int Gynecol Cancer Soc 2002;12:475-9.

46. Lin S-J. Factors influencing the uptake of screening services for breast and cervical cancer in Taiwan. $J R$ Soc Promot Heal 2008;128:327-34.

47. Akinyemiju TF. Socio-economic and health access determinants of breast and cervical cancer screening in low-income countries: analysis of the World Health Survey. PLOS ONE 2012;7:e48834.

48. Gamarra CJ, Paz EPA, Griep RH. Social support and cervical and breast cancer screening in Argentinean women from a rural population. Public Health Nurs 2009;26:269-76.

49. Abotchie PN, Shokar NK. Cervical cancer screening among college students in Ghana: knowledge and health beliefs. Int J Gynecol Cancer Off J Int Gynecol Cancer Soc 2009;19:412-16.

50. Byrd TL, Chavez R, Wilson KM. Barriers and facilitators of cervical cancer screening among Hispanic women. Ethn Dis 2007;17:129-34. 